\title{
Governing Risks of Multi-Use: Seaweed Aquaculture at Offshore Wind Farms
}

\author{
Sander W. K. van den Burg ${ }^{1 *}$, Christine Röckmann ${ }^{1}$, Jennifer L. Banach ${ }^{2}$ and \\ Luc van Hoof ${ }^{3}$ \\ ${ }^{1}$ Wageningen Economic Research, Wageningen University and Research, Wageningen, Netherlands, ${ }^{2}$ Wageningen Food \\ Safety Research, Wageningen University and Research, Wageningen, Netherlands, ${ }^{3}$ Wageningen Marine Research, \\ Wageningen University and Research, Wageningen, Netherlands
}

\section{OPEN ACCESS}

Edited by:

Di Jin,

Woods Hole Oceanographic Institution, United States

Reviewed by:

Scott Lindell,

Woods Hole Oceanographic Institution, United States

Hauke Kite-Powell,

Woods Hole Oceanographic Institution, United States

Tiffany Smythe,

United States Coast Guard Academy

United States

${ }^{*}$ Correspondence:

Sander W. K. van den Burg sander.vandenburg@wur.n

Specialty section:

This article was submitted to Marine Affairs and Policy,

a section of the journal

Frontiers in Marine Science

Received: 30 May 2019

Accepted: 28 January 2020

Published: 20 February 2020

Citation:

van den Burg SWK, Röckmann C,

Banach JL and van Hoof L (2020)

Governing Risks of Multi-Use:

Seaweed Aquaculture at Offshore

Wind Farms. Front. Mar. Sci. 7:60.

doi: 10.3389/fmars.2020.00060
Spatial claims concerning the rapidly growing European offshore wind sector give rise to various ideas for the multi-use application of wind farms. Seaweed is considered a promising feedstock for food and feed that could be produced at offshore wind farms. Concerns about risks resulting in liability claims and insurance premiums are often seen as show-stoppers to multi-use at offshore wind farms. In this study, key environmental risks of seaweed cultivation at offshore wind farms, identified through literature review, are characterized based on stakeholder consultation. The current approach to risk governance is evaluated to assess how it can handle the uncertain, complex, and/or ambiguous risks of multi-use. It is concluded that current risk governance for multi-use is poorly equipped to deal with the systemic nature of risks. Risk governance should be a joint effort of governments and private regulators. It can improve if it is based on an adaptive framework for risk assessment that can deal with complex, systemic risks. Furthermore, it should be flexible and inclusive, i.e., open to new incoming information and stakeholder input, and taking into account and communicate about the different stakes and values of the various parties involved. The importance of communication and inclusion must be recognized, which promotes participation of concerned stakeholders.

Keywords: risk governance, multi-use at sea, seaweed, public regulation, private standards

\section{INTRODUCTION}

The rapid growth of offshore wind farms in the North Sea and the resulting claim for ocean space drive interest for the multi-use of these wind farms (Stuiver et al., 2016; Legorburu et al., 2018). Among the studied multi-use initiatives with offshore wind is that with seaweed cultivation (Wever et al., 2015; Jansen et al., 2016). Seaweed can be cultivated in European seas (Van den Burg et al., 2016; Bak, 2018) and is considered a promising (protein) source for food, feed, and the bio-based economy. Recent studies have investigated the potential for seaweed-based food products (Wells et al., 2017; Kazir et al., 2018) and applications in the feed market (Li et al., 2018a,b; Wan et al., 2018).

The further development of multi-use combinations offshore does, however, pose risks for the environment, human health, along with food and feed safety (Michler-Cieluch et al., 2009; Wever et al., 2015). Since seaweed cultivation offshore in a multi-use setting is still being developed, it is not clear how various safety aspects should be governed, i.e., addressed, assessed, and managed. 
Seaweed aquaculture in an offshore wind farm will have environmental impacts. Exploratory studies point to both negative and positive effects (Zhang et al., 2009; Cabral et al., 2016). Positive effects include the use of seaweed for the bioremediation of contaminants or seaweed farms providing sheltered areas for nature (Ólafsson et al., 1995; Stephens et al., 2014; Buschmann et al., 2017; Wood et al., 2017).

The subject of this study is a hypothetical combined seaweedoffshore wind park. The objective to identify and characterize the risks of combining two activities, with a focus on environmental and related food and feed safety risks. ${ }^{1}$ The main question is: What type of risk governance is needed to cope with the risks of multi-use at sea? The following sub-questions are identified:

1. Which environmental risks are of concern? (Section "Which Risks Are of Concern to Respondents?")

2. How can these risks be characterized? (Section "How Can These Risks be Characterized?")

3. How are these risks currently governed and are the existing approaches considered relevant? (Section "How Are These Risks Currently Governed?")

4. Is current risk governance capable of handling these environmental risks? (Sections "Respondents' Evaluation of Current Risk Governance - An Assessment From a Risk Governance Perspective")

5. How can risk governance of multi-use at sea be improved? (Section “Conclusion”).

European stakeholders were interviewed; hence, this paper focusses on the safety aspects of multi-use in European waters. Also, the paper focuses on seaweed for human consumption and animal feed, excluding other applications such as additives, biofuels, and cosmetics.

\section{METHODOLOGY}

In order to identify what type of risk governance is suitable to cope with the risks of multi-use at sea, we identified risks of multi-use, studied how these risks are currently dealt with, and evaluated existing regulations with stakeholders. Various methods were used, each contributing to answering multiple research questions (see Table $\mathbf{1}$ below for an overview).

\section{Literature Review}

A database of environmental risks of seaweed aquaculture was compiled based on a scientific literature review. The database contained $>100$ entries, which were subsequently grouped by relevance. The following criteria were used to determine the relevance of each of these risks:

- Whether or not the risk in an environmental risk. Risks that exclusively relate to technical operations, human health and safety, were excluded (these risks are described in some of the project deliverables, e.g., Vredeveldt et al., 2017);

\footnotetext{
${ }^{1}$ Food and feed safety risks that cannot be attributed to the combination of activities, e.g., the natural accumulation of iodine, are excluded from this analysis.
}

- the extent to which the risk increases in likelihood or impact in a multi-use combination, i.e., the combined production of wind and seaweed; and

- the extent to which the risk impacts the long-term sustainability of seaweed and wind production, either because of ecosystem changes or increased societal resistance.

\section{Workshop}

The literature review was used as input for a workshop (June 2017) with over 30 experts interested in safety aspects of offshore multi-use. The study team presented the top five of highest ranking risks to the workshop participants, followed by a discussion. After discussing, the participants were asked (1) if additional risks were to be included and (2) if the ranking of risks needed to be changed. Participants comprised scientists, practitioners, and managers and were affiliated to organizations such as the Stichting Noordzeeboerderij, Alfred Wegener Institute (Bremerhaven), Shell/NoordzeeWind, and the Netherlands Food and Consumer Product Safety Authority (NVWA). In total 32 participants joined the workshop with various backgrounds as presented in Table 2 below.

During the workshop sessions, participants evaluated our preliminary, literature-based risk overview as well as provided additional expert knowledge of and insight into the identified risks.

\section{Interviews and Survey}

Between September 2017 and April 2018, seven in-depth interviews were held with European stakeholders involved with

TABLE 1 | Relation between research questions and methods.

\begin{tabular}{lccc}
\hline Research questions & $\begin{array}{c}\text { Literature } \\
\text { review }\end{array}$ & Workshop Survey Interviews \\
\hline $\begin{array}{l}\text { Which environmental risks are of } \\
\text { concern? }\end{array}$ & $X$ & $X$ & \\
How can these risks be & $X$ & $X$ & \\
characterized? & & $X$ \\
How are these risks currently \\
governed and are the existing \\
approaches considered relevant \\
Is current risk governance \\
capable of handling these \\
environmental risks? \\
How can risk governance of \\
multi-use at sea be improved?
\end{tabular}

TABLE 2 | Breakdown of workshop participants.

Background

Number of participants

Industry (including seaweed and offshore wind sector)

7

Non-governmental organization

3

Government

Science

3

Independent
18

1 
seaweed cultivation and safety. The objective of these interviews was to discuss environmental risks and the extent to which existing regulation is able to deal with these risks. Interviews used a semi-structured questionnaire (see Supplementary Materials). Respondents were selected (a) because they had practical experience in the sectors concerned and (b) to represented a variety of backgrounds including seaweed cultivators, offshore wind sector and certification agencies. A survey was developed to collect information on relevant private and public standards for the seaweed sector (see Supplementary Materials).

Additionally, a project mailing list $(n=253)$ with recognized stakeholders from seaweed aquaculture and/or offshore wind energy was used. The survey was opened twice (29-4-2018 to 2905-2018 and 20-6-2018 to 20-07-2018), and an online survey tool was used (SelectSurvey). The survey was designed to assess which regulations and standards are most often used by the sectors, and if these regulations and standards are considered capable to cope with the identified risks. Respondents were guaranteed that the data collected in this survey would be statistically analyzed, used for scientific publications, and that answers provided would never be presented or published at the company or individual level. All respondents remained anonymous. Despite significant outreach, only 12 complete responses were received. Results from the survey are therefore not presented separately but shown as additional expert inputs along with the results from the qualitative interviews.

\section{Limitations to the Study}

The methods chosen for this study and the low number of respondents to the survey limits the validity of the findings in two ways. First, the evaluation of risks is not based on a large number of practical experiences (not in the least because there is limited experience) and should not be taken as a definitive assessment.

Secondly, the findings are mainly based on experiences with offshore wind energy and seaweed cultivation in Europe and the United States. The long-standing experience with seaweed cultivation in Asia are not well-reported in the international scientific literature, nor did the companies respond to the survey.

\section{Theoretical Concepts for Assessing Risk Governance \\ From Simple to Systemic Risks}

Risk assessment refers to efforts to think about what might cause harm to people, infrastructures, and the environment. Assessing risk, in terms of probability and effect, dose and response, and agent and consequences, has been common practice for a long time (Renn et al., 2011). The International Maritime Organization (IMO) formulated a Formal Safety Assessment (FSA) based on this rationale. It comprises five steps. After (1) hazard identification and (2) risk analysis, risk control options are formulated (3), and a cost-benefit assessment is performed (4). The FSA ends with (5) recommendations for policymakers. The term "formal" refers to the use of mathematical logic to reason the safety assessment process, as illustrated by proposed methods such as fault and event trees (Kontovas, 2008; Bozzano, 2011). Framing risks as calculable and predictable has led to the development of technocratic, decisionistic, and economic models of risk assessment and management (Renn et al., 2011). It has become clear that such models are only used for specific types of "simple risks" where the cause is well known, the potential negative consequences are apparent, the uncertainty is low, and there is hardly any ambiguity regarding the interpretation of the risk. In other words, the IMO Formal Safety Assessment, designed to assess maritime safety e.g., shipping, cannot be used to assess complex environmental risks.

Simple risks, which are suitable for mathematical evaluation and in which uncertainty, complexity, and ambiguity are low (Netherlands Scientific Council for Government Policy [WRR], 2009), are not the norm, but an exception. Societies now are aware they also face "systemic risks," denoting the fact that risks to human health and the environment are embedded in a broader context of social, financial, and economic risks and opportunities (Beck, 1992; Renn and Klinke, 2004). These systemic risks cannot be reduced to numerically defined probability distributions (Van Asselt and Renn, 2011). Systemic risks require a holistic approach to risk identification, assessment, and management because investigating systemic risks goes beyond the usual agentconsequence analysis (OECD, 2003). Risk-based methods in food safety governance also recognized the complexity of risk. Beyond that, the precautionary principle addresses circumstances of incertitude, including uncertainty, ambiguity, and ignorance, the latter of which occurs when probabilities and outcomes may not yet be characterized (Dreyer and Renn, 2009).

For risk assessment and governance, it is therefore important to be aware of the nature of risks. Based on Van Asselt and Renn (2011), three characteristics of systemic risks are presented that set them apart from simple risks: complexity, uncertainty, and ambiguity.

\section{Complexity}

With this first characteristic, if there is a clear causal relationship between an event and an effect, complexity is low. As other factors (e.g., environment conditions) or variables (e.g., weather) influence the occurrence of effects, complexity increases. Complexity can be caused by interactive effects among agents (synergisms or antagonisms), long delay periods, inter-individual variation, etc. Due to the complexity, it is impossible to achieve complete deterministic knowledge of cause-effect relationships.

\section{Uncertainty}

This second characteristic points to the high uncertainty when assessing or appraising risks pertaining to future events or consequences (Van Asselt and Renn, 2011). The potential outcomes may be clear, but the ability to quantify the probabilities is not; hence, it leads to varying degrees of uncertainty. For example, uncertainty is higher when dealing with new products or new production processes since limited to no reference data is available.

\section{Ambiguity}

This third characteristic implies that there are different legitimate viewpoints from which to evaluate whether there are or could be adverse effects and whether these risks are tolerable or even acceptable (Van Asselt and Renn, 2011). 


\section{Risk Governance}

Dealing with risks is not solely the responsibility of governments. The concept of governance can be used to signify the move away from full state-responsibility ("government"). It captures various dynamics; e.g., the regulation of publicly relevant issues by non-state actors and the inclusion of actors in states' policy making, without being able to mandate and sanction such cooperation (Offe, 2009). Governance includes formal institutions and regimes and informal arrangements. It refers to the totality of actors, rules, conventions, processes, and mechanisms concerned with how relevant risk information is collected, analyzed, and communicated, and how regulatory decisions are taken (IRGC, 2005, 2007; van Asselt, 2007). Risk governance involves the "translation" of the substance and core principles of governance into the context of risk and risk-related decision-making (Renn and Klinke, 2015).

Principles for "risk governance" come from an ambition to provide a conceptual as well as a normative basis for how to deal responsibly with uncertain, complex, and/or ambiguous risks (Van Asselt and Renn, 2011). The nature of systemic risks requires cooperation, coordination, and trust between a range of stakeholders who have diverging interests and different perceptions of the (potential) risks involved. Van Asselt and Renn (2011) define three principles to shape risk governance of the complex, uncertain, and/or ambiguous risks: communication and inclusion; integration; and reflection.

\section{Communication and Inclusion}

This first principle aims to provide a better basis for responsible governing of complex, uncertain, and/or ambiguous risks. Contrary to the current state of affairs, in which risk topics are usually identified by experts, public values and social concerns may act as the driving agents for identifying risk topics. Inclusion does not just mean that various actors are included, but that they play a key role in framing (or pre-assessing) the risk (IRGC, 2005; Renn and Walker, 2008; Roca et al., 2008).

\section{Integration}

The second principle, integration, refers to the need to collect and synthesize all relevant knowledge and experience from various disciplines and various sources taking into account uncertainty and (differing) articulations of risk perceptions and values. It implies that a strict separation between risk assessment and risk management is counterproductive. Risk governance is not a linear, sequential three-stage process of risk assessment, management, and communication, but it is dynamic and requires interlinked and iterative processes.

\section{Reflection}

The third principle concerns reflection. It emphasizes that there are important, yet difficult issues (complexity, uncertainty, ambiguity, and consequentially balancing different views of the need to take action) that need repeated consideration of all actors throughout the process. Otherwise, the process jeopardizes (re)introduction of the familiar frames and routines developed for simple risks.
In Section "Discussion," we return to these principles to evaluate current risk governance and formulate recommendations for improving risk governance.

\section{RESULTS}

\section{Which Risks Are of Concern to Respondents?}

The literature review and the workshop identified five key risks related to cumulative effects and interactions (Van den Burg and Röckmann, 2017). Subsequently, stakeholders were asked to reflect on these five risks in interviews and a survey. Figure 1 shows the frequency with which these five risks are believed to have a potentially negative (dark) or a positive (light) impact, based on the responses provided. Responses came from 7 interviewees and 12 survey respondents; respondents could give multiple answers.

Few respondents considered ecosystem change and decreased primary production as a potential negative effect of seaweed cultivation at an offshore wind-farm. The other three risks were mentioned more often. Interestingly, other risks were not only seen as potentially negative; according to half of the respondents, seaweed farming can have a positive effect on its surrounding such as bringing more biodiversity, attracting birds and mammals, and/or taking up pollution from the environment. The evaluation of risks is not based on a large number of practical experiences (not in the least because there is limited experience) and should not be taken as definitive assessment.

\section{How Can These Risks Be Characterized?}

Based on literature concerning systemic risks, Table 3 was constructed to help characterize the risk of multi-use of seaweed cultivation at an offshore wind farm.

The five identified environmental safety risks (Section "Which Risks Are of Concern to Respondents?") are characterized in Table 4, reflecting on complexity, uncertainty, and ambiguity. This characterization is prepared by the project team, drawing upon the findings from the literature review and the workshop. The overview below shows the different nature of the five risks addressed.

\section{Ecosystem Change Due to Increased Sedimentation}

Changes to the ecosystem are discussed as a risk of seaweed aquaculture. Increased sedimentation is reported by various authors as a risk of aquaculture (Buschmann et al., 1996; Eng et al., 1989; Zhang et al., 2009). The sedimentation of fall-off seaweeds could lead to organic enrichment. Through degradation and mineralization, this organic material can become a source of food for other species in the ecosystem. The fall-off effect is potentially stronger in a combined seaweed and wind farm system where wind turbine foundations cause disturbances in the water layers (Vanhellemont and Ruddick, 2014). At the same time, these disturbances might result in rapid dilution of organic matter.

The extent to which this negatively affects the ecosystem depends on local environmental, meteorological, and 


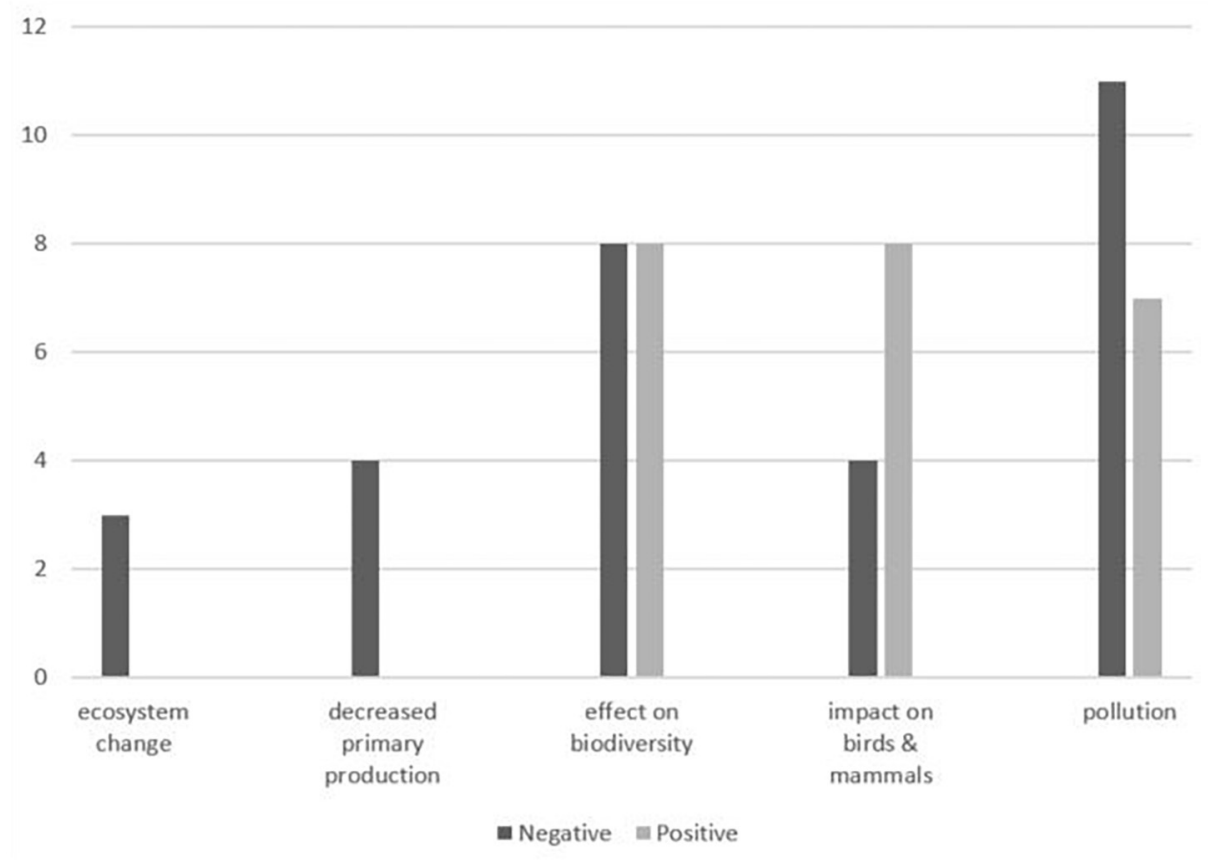

FIGURE 1 | Environmentral risk of concern according to respondents.

oceanographic conditions; thus, making this risk highly complex. Uncertainty is medium; there are no reported problems with increased sedimentation due to seaweed farming, but the topic is studied (Wood et al., 2017). This risk was infrequently considered relevant by respondents in interviews and the survey. Nevertheless, they generally accepted that increased sedimentation represents a negative effect; ambiguity is, therefore, low.

\section{Decreased Primary Production}

The combined impact of wind turbines causing a disturbance in the water column and growth of seaweed can negatively affect primary production in the area, also given the impact of offshore

TABLE 3 | Scoring table for the characterization of environmental safety risks by respondents based on interviews and survey (source: authors).

\begin{tabular}{|c|c|c|c|}
\hline & High & Medium & Low \\
\hline Complexity & $\begin{array}{l}\text { Multiple external } \\
\text { variables interfere } \\
\text { with cause-effect } \\
\text { relation }\end{array}$ & $\begin{array}{l}\text { One external } \\
\text { variable interferes } \\
\text { with cause-effect } \\
\text { relation }\end{array}$ & $\begin{array}{l}\text { No external variable } \\
\text { interferes with } \\
\text { cause-effect relation }\end{array}$ \\
\hline Uncertainty & $\begin{array}{l}\text { No reliable } \\
\text { information } \\
\text { available, from } \\
\text { sector nor } \\
\text { comparable sectors }\end{array}$ & $\begin{array}{l}\text { Reliable information } \\
\text { available comes } \\
\text { from comparable } \\
\text { sectors and } \\
\text { activities }\end{array}$ & $\begin{array}{l}\text { Reliable information } \\
\text { available, based on } \\
\text { experiences in the } \\
\text { sector concerned }\end{array}$ \\
\hline Ambiguity & $\begin{array}{l}\text { No consensus on } \\
\text { whether an impact is } \\
\text { positive or negative }\end{array}$ & $\begin{array}{l}\text { Minority deviates } \\
\text { from consensus on } \\
\text { whether an impact is } \\
\text { positive or negative }\end{array}$ & $\begin{array}{l}\text { Consensus on } \\
\text { whether an impact is } \\
\text { positive or negative }\end{array}$ \\
\hline
\end{tabular}

wind on ocean circulation (Broström, 2008). Eklöf et al. (2005) reported how shading due to seaweed aquaculture could impact the ecosystem. If a seaweed farm is located above or near an area of a natural hard substrate where seaweeds grow naturally, the naturally grown seaweed below is potentially outcompeted by the farmed seaweed due to the absorption of the sunlight near the surface. Competition for nutrients might occur; the nutrients taken up by seaweed are not available to other species. In some locations with a nutrient surplus, seaweed cultivation can have a positive impact by removal of excess nutrients (Kim et al., 2014).

This risk is highly complex. Though causal mechanisms are known, the occurrence of this effect is dependent not only on the scale of production but also on light and nutrient availability as well as ecosystem characteristics. Uncertainty is medium as there are no reported problems of decreased primary production due to seaweed production, yet the causal relationship between nutrient and light availability and primary production are known. Ambiguity is low as a decrease in primary production is generally seen as negative with a negative impact on other organisms in the food web. This risk is rarely considered relevant by respondents in interviews and the survey.

\section{Effect on Biodiversity, Including Invasive Species, and Bioinvasions}

Seaweed cultivation can cause effects on biodiversity, including the possibility of introducing invasive species, bio-invasions (Bindu and Levine, 2011), and potential species translocations (Beveridge et al., 1997). Concerning offshore wind, there is a danger that the hard substrate of the foundations and turbines come to serve as stepping-stones by enabling further distribution 
TABLE 4 | Characterization of environmental safety risks.

\begin{tabular}{|c|c|c|c|c|c|c|}
\hline \multirow{2}{*}{$\begin{array}{l}\text { Risk } \\
\text { Ecosystem change due } \\
\text { to sedimentation }\end{array}$} & \multicolumn{2}{|r|}{ Complexity } & \multicolumn{2}{|r|}{ Uncertainty } & \multicolumn{2}{|r|}{ Ambiguity } \\
\hline & High & $\begin{array}{l}\text { Dependent on environmental, } \\
\text { meteorological, and ocean } \\
\text { conditions }\end{array}$ & Medium & $\begin{array}{l}\text { No reported problems; does occur } \\
\text { with other forms of aquaculture }\end{array}$ & Low & $\begin{array}{l}\text { Generally accepted; sedimentation } \\
\text { is a negative effect }\end{array}$ \\
\hline $\begin{array}{l}\text { Decrease primary } \\
\text { production }\end{array}$ & High & $\begin{array}{l}\text { Complex due to interactions at the } \\
\text { ecosystem level }\end{array}$ & Medium & $\begin{array}{l}\text { Not a currently reported issue of } \\
\text { seaweed production }\end{array}$ & Low & $\begin{array}{l}\text { Generally accepted; shading is a } \\
\text { negative effect }\end{array}$ \\
\hline Effect on biodiversity & High & $\begin{array}{l}\text { Due to ecosystem interactions } \\
\text { (e.g., trophic/food-web, population } \\
\text { structures) }\end{array}$ & High & $\begin{array}{l}\text { No earlier experiences or empirical } \\
\text { data; knowledge gaps }\end{array}$ & High & $\begin{array}{l}\text { Seen as a negative and a positive } \\
\text { effect; it depends on the } \\
\text { perspective }\end{array}$ \\
\hline Impact on animals & Medium & $\begin{array}{l}\text { Occurrence is easy to evaluate, but } \\
\text { effects at the population-level are } \\
\text { complex }\end{array}$ & Medium & $\begin{array}{l}\text { No experiences with the effects of } \\
\text { large-scale farming }\end{array}$ & High & $\begin{array}{l}\text { Generally accepted; this is a } \\
\text { negative effect }\end{array}$ \\
\hline Pollution & Low & $\begin{array}{l}\text { Known causal relations, causal } \\
\text { relations and dispersion models }\end{array}$ & Medium & $\begin{array}{l}\text { Accumulation is a known, impact of } \\
\text { incidents not known }\end{array}$ & Low & $\begin{array}{l}\text { Pollution is unanimously considered } \\
\text { to be negative }\end{array}$ \\
\hline
\end{tabular}

of invasive species. Petersen and Malm (2006) described the impact of the "reef-effect" of a hard substrate on habitat and species composition. In combination with seaweed cultivation, the wind turbines can act as "stepping stones" multiplying the risk of introduction and further distribution of exotic species. The presence of a seaweed farm (offshore or nearshore) can amplify the risk of exotic species invasion. The multi-use setting poses a potential cumulative effect because both activities introduce additional artificial hard substrates to the environment, and the presence of seaweed itself can be a stepping stone or substrate for exotic species.

Complexity is high because the impact of combined seaweed and energy production on biodiversity is dependent on various other factors, including developments in adjacent areas and quality of water. An important ecological question is whether such nurseries are additional nursery areas or whether fish have abandoned their original nursery areas, which might result in other ecosystem changes. Uncertainty is high; there is currently no clear-cut view on the effect of seaweed farming on biodiversity. The claim that wind farms can be nursery areas for fish needs scientific validation. Ambiguity is high with positive and negative views on the effect of seaweed farming existing side by side. Respondents which farm seaweed themselves have observed the increased presence of crustaceans, fish, and birds in the area. However, translocations and facilitating invasive species are considered a negative effect, disturbing ecosystems beyond the boundaries of an individual offshore wind farm. Effects on biodiversity are reported by multiple respondents and illustrating the highly ambiguous nature of this risk - generally considered a positive asset of seaweed farming.

\section{Impact on Animals, Including Birds, Marine Mammals, and Bats}

Offshore wind farms and other marine constructions can have an impact on flora and fauna. The addition of hard substrates creates a new area for the potential settlement of species, while the (partial) closure of areas for other activities - like fishing - can lead to "sheltered areas." Petersen and Malm (2006) described changes in marine mammal abundance around wind farms due to added hard substrate and increased food availability. Since seaweed farms are also considered to stimulate local biodiversity, the combination of wind and seaweed farming can have a more substantial positive effect. However, this is potentially also a negative effect. For example, large mammals can get stuck in structures (Stelzenmüller et al., 2016), while bird and bat mortality can increase due to collisions with turbines or turbine blades (Furness and Tasker, 2000; Lagerveld et al., 2014; Röckmann et al., 2015). If the seaweed farms attract avian predators, the combination of wind with seaweed farming might even lead to increased bird or bat mortality; for marine mammals, an offshore seaweed farm can pose a possible barrier effect due to the "closed" construction (Lagerveld et al., 2014).

Although the causal relationship for this risk is relatively straightforward (e.g., collision, entanglements), the eventual effect on animal populations depends on some other variables and complexity of this risk is considered medium. Uncertainty is also considered medium, given that experiences with seaweed farming are rare, but impacts on marine animals are known for other sectors. The ambiguity is high as respondents considered both positive and negative impacts for this risk.

\section{Pollution}

Pollution in the marine environment can be taken up by the growing seaweeds, rendering them potentially unsafe for food and feed applications. This risk is recognized by all respondents. Seaweeds are known to accumulate heavy metals; the question is whether or not levels pose a human or animal health risk (Roleda et al., 2018). From a multi-use perspective, the question here is whether multi-use of seaweed cultivation at an offshore wind farm increases the chances of this happening. The infrastructures for offshore wind energy generation must be protected against corrosion and biofouling. The substances used for this protection may pollute the seaweed produced, and vice versa, the presence of an aquaculture facility might increase corrosion and biofouling of infrastructures. For examples of how this occurs, see Lagerveld et al. (2014) and Klijnstra et al. (2017). The potential impact of both processes is high, also affecting the integrity of structures and eventual safety of produced seaweed food and feed purposes.

The complexity of this risk is low, with known causal relationships, effect chains and models to evaluate dispersion 
of pollutants in the environment. Uncertainty is considered medium. Although it is known that some pollutants accumulate in seaweed, less is known about the impact of incidents, with temporarily high exposure to pollutants, on the seaweed. This knowledge gap adds to the complexity. In terms of ambiguity, there is no disagreement on the need to avoid pollution of seaweeds, meaning ambiguity is low. In interviews and the survey, this issue is considered of main concern. Although there are no reported experiences with wind farm accidents affecting seaweed, this evident concern of stakeholders may be explained by ongoing discussions on levels of arsenic and iodine in seaweed.

\section{How Are These Risks Currently Governed?}

Understanding the dynamics, structure, and functionality of risk governance processes related to multi-use offshore requires a comprehensive understanding of the governance system. Seaweed aquaculture in a multi-use setting is still a hypothetical construct. Current risk governance is shaped by a patchwork of public and private rules and standards. Two main building blocks of regulation can be identified: government regulation and private standards.

\section{Government Regulations}

Several government regulations concerning environmental and ecosystem impacts exist. Key legislation in the field of food and feed safety relevant to seaweed production is also discussed because of their potential interactions, for example, due to biodiversity or pollution.

\section{Environmental impact}

The Marine Strategy Framework Directive aims to achieve Good Environmental Status (GES) of the EU's marine waters by 2020 and to protect the resource base upon which marine-related economic and social activities depend (Directive 2008/56/EC). Member-states must ensure GES is reached. The impact of new activities to be undertaken are evaluated in the planning and permitting stages. This impact evaluation is performed with an environmental impact assessment. The environmental impact assessment Directive (2011/92/EU) and its amendment Directive 2014/52/EU outline the procedure for environmental impact assessment as a procedure to ensure that the environmental implications of decisions are considered before the decisions are made. Environmental impact assessment can be undertaken for individual projects, such as the construction of a dam, motorway, airport, or factory (on the basis of Directive 2011/92/EU; known as Environmental Impact Assessment - EIA Directive) or for public plans or programs (on the basis of Directive 2001/42/EC; known as Strategic Environmental Assessment - SEA Directive). The common principle of both directives is to ensure that those plans, programs, and projects that are likely to have significant effects on the environment are made subject to an environmental assessment before their approval or authorization.

Organic certification of seaweeds is already regulated through Regulation (EC) 834/2007 and Regulation (EC) 889/2008 and amendments in Regulation (EC) 710/2009. While this regulation has been the basis for organic labeling of seaweeds, especially in France, various other EU countries do not have certified seaweed producers.

\section{Food and feed safety impact}

Global food safety governance is supported by international organizations like the World Health Organization (WHO), World Trade Organization (WTO), and Codex Alimentarius Commission (CAC). For example, the CAC develops and maintains the Codex Alimentarius, which is a collection of international standards, codes of practices, guidelines, i.a. concerning food (safety) and production. Food hygiene is also integrated into the Codex Alimentarius; it includes the Hazard Analysis and Critical Control Point (HACCP) system, which helps support food safety management. At the European level, the foundation for food and feed safety law is the General Food Law [Regulation (EC) 178/2002]. In addition to these standards and regulations, more detailed legislation for food (and feed) safety exist which e.g., specify maximum allowable concentrations of contaminants that could be present in food or feed ingredients.

\section{Private Standards}

In addition, to the legal norms and methods described above, respondents reported many private standards that are relevant regarding safe seaweed production.

\section{Environmental impact}

Additional certification to highlight the environmental-friendly nature of production can be achieved, through the MSC/ASC label for seaweed. The Marine Stewardship Council (MSC) and Aquaculture Stewardship Council (ASC) have released a joint standard for sustainable seaweed production, setting many requirements for seaweed harvesting and farming practices.

\section{Food and feed safety impact}

A variety of private standards for food and feed safety are considered relevant when it comes to safe seaweed. Three standards - the International Standards Organization (ISO) 22000:2018, British Retail Consortium (BRC), and GLOBALG.A.P. - had been mentioned by respondents (see Section "Private Standards"). Other standards co-exist, including, i.a., the International Featured Standards (IFS), Food Safety System Certification (FSSC), and Good Manufacturing Practices (GMP).

ISO 22000:2018 provides the principles and specifies the basic requirements for the design and implementation of a feed and food traceability system. It can be applied by an organization operating at any step in the feed and food chain and is intended to be flexible enough to allow feed and food organizations to achieve identified objectives.

The BRC Global Standard for Food Safety is developed by food industry experts from retailers, manufacturers, and food service organizations; it was first published in 1998. The BRC Global Standard provides a framework to manage product safety, integrity, legality and quality, and the operational controls for these criteria, in the food and food-ingredient manufacturing, processing, and packing industry.

Good Agricultural Practices (GAP) standards have been developed by the food industry and producer organizations to 
formulate standards for agricultural practices at the farm level. For instance, the GLOBALG.A.P. Aquaculture Standard sets criteria for legal compliance, food safety, workers' occupational health and safety, animal welfare, and environmental and ecological care. The GLOBALG.A.P. Aquaculture Standard applies to a diversity of fish, crustaceans, and mollusks and extends to all hatchery-based farmed species, as well as the passive collection of seedlings in the planktonic phase. It covers the entire production chain, from broodstock, seedlings and feed suppliers to farming, harvesting, and processing. Aquaculture producers are required to source the compound feed used at the aquatic farming hatchery levels from reliable suppliers.

\section{Which standards are considered relevant by respondents?}

As seen in Section "How Are These Risks Currently Governed?" various standards are potentially relevant for seaweed. Figure 2 combines results from the interviews and survey to illustrate how often particular standards were considered relevant by respondents. Various respondent explicitly indicated that particular standards are irrelevant to them (Figure 2).

The variety of relevant standards is reflected in Figure 2, as is the lack of a "dominant" standard. The four standards that are most often considered relevant (BRC, ISO22000, organic, and MSC/ASC) were also the ones most often considered irrelevant. Other standards were mentioned occasionally. Given the limited number of respondents and the geographical bias, these results should be considered indicative.

Private standards related to the environmental impact of production, the EU organic and MSC/ASC labels, are not unequivocally welcomed by respondents. When it comes to organic labeling, some state, "they are rarely asked for" while others see this as a crucial element in setting their production apart from others and have applied for certification. Some are certified based on a comparable national standard.
The MSC/ASC seaweed label is newly developed - as a general standard to seaweed production, and not focused explicitly on multi-use - and was unknown to some respondents. Among those who are familiar with the label, some see it as relevantly showcasing the sustainability and natural character of seaweed. Others argue that the strong association of MSC/ASC with fish renders it useless for seaweeds.

\section{DISCUSSION}

The results presented in Sections "Which Risks Are of Concern to Respondents?" and "How can these risks be characterized?" are discussed from two perspectives. First, the respondent perspective is taken. In the interviews and survey, respondents reported on how both government regulation and private standards are used in securing safety in their operations. Secondly, current risk governance is assessed from a "risk governance" perspective (relating to Section "Risk Governance").

\section{Respondents' Evaluation of Current Risk Governance}

Regulating Safe Seaweed Production Is in Its Infancy Risk governance of seaweed production in a multi-use setting is still in its infancy. Corporate responsibility and private standards are key components of contemporary seaweed risk governance. Whether imposed by value chain actors or pushed by critical non-governmental organizations and consumers, the challenge is to show how operations can be safe. Standardization and verification are of added value as they can result in standard protocols for monitoring and assessment.

Both public and private regulations are, as of now, not specified to deal with seaweed - let alone seaweed produced in a multi-use setting - even though their impact might be

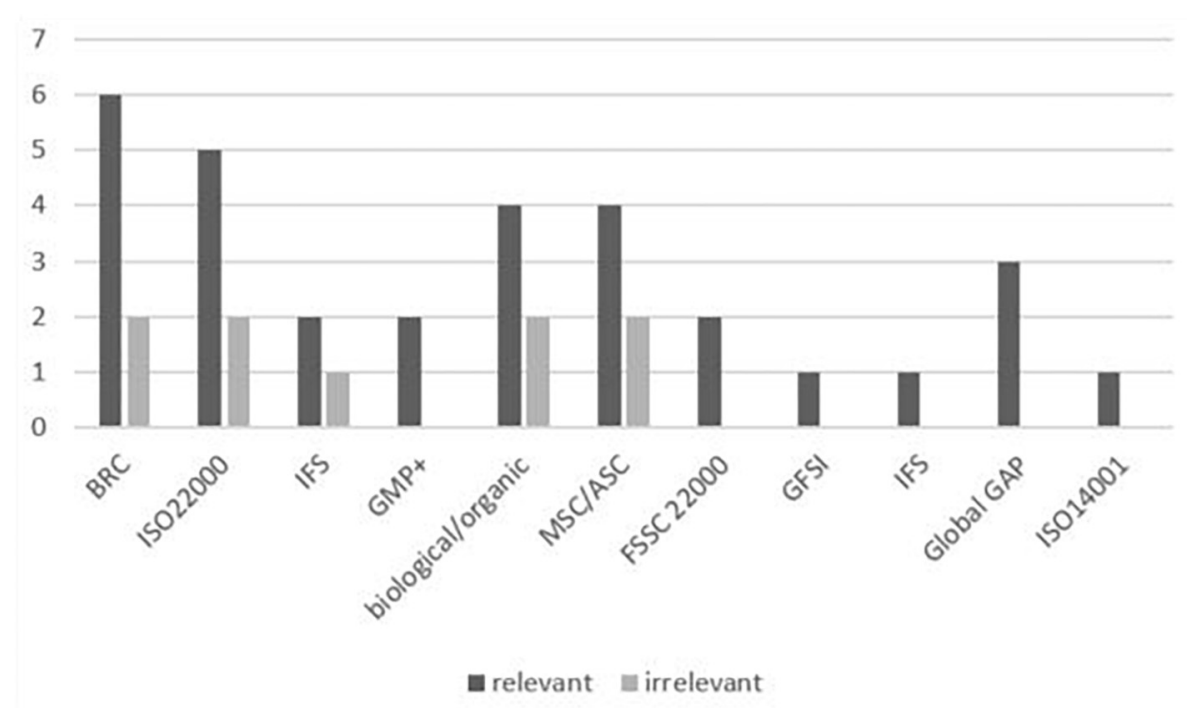

FIGURE 2 | Relevance of private standards accordings to responds. Not mentioned in text are GMP+, Global food safty Initiative (GFSI) and ISO14001. These standards are deemed relevant for seaweed by some of the respondents. 
far-reaching. Consequentially, businesses, policy-makers, and certification bodies take up standards and norms from adjacent fields. There is no consensus on which standards and norms to use nor is there a uniform approach to securing environmental as well as food (and feed) safety, apart from the legally required minimum. On a positive note, this allows producers to work with tailored approaches. On a negative note, each of them must then "reinvent the wheel."

Concerning environmental safety, the minimum requirements are set by the obligation to address environmental impact in applying for permits to produce seaweed. For food and feed safety, the minimum is comprised of those principles, requirements, and procedures laid down in global and national legalization.

Nonetheless, there are efforts to implement and enforce stricter standards. Almost all respondents impose additional requirements to secure environmental and food (and feed) safety. These requirements range from organic labeling and MSC/ASC certification to implementing one of the various private food safety standards. What is most striking are the differences in attitude toward these standards, where for every advocator, there is a critic.

\section{Legal Norms Provide Limited Guidance}

Legislation for managing environmental impacts is not written specifically for seaweed farming and multi-use. The interviewed seaweed farmers had to show authorities that their operations come with little environmental impact, but they did not go through a formal environmental impact assessment. This exemption might be explained by the limited scale of farming and sometimes even experimental character of seaweed farms.

The legislation for food safety is written less specific to seaweed as a product. In the EU, the General Food Law is the basis for food safety. There is little guidance as on how to interpret existing norms for seaweed. Various respondents see this lack of guidance - which creates room for varying interpretations as a missed opportunity. The food safety issues considered by respondents as most pressing bear no directly apparent relation to multi-use. For instance, producers, governments, and retailers all showed concerns about toxic heavy metals, like arsenic, and iodine.

\section{Various Private Standards for Food Safety Are Used Yet Are Open to Interpretation}

All respondents see the value of private standards for food safety. Food safety certification is a "license-to-produce" imposed by retailers on the value-chain. Although different private standards are used, the consensus is that ISO-22000 is a basic standard for food safety and a good starting point. Once a company grows, and clients demand more evidence related to food safety, other standards become relevant (e.g., BRC). These standards are based on legal norms but require additional safety measures and monitoring to be in place.

These standards do not explicitly describe safe seaweed production and processing. The lack of such detailed standards provides the freedom to make ones' own requirements depending on the influx of variables to consider (type of seaweed, way of processing, end-product use, etc.). This approach is the essence of private food safety management, where the responsibility to have safe food products lies with the food (or feed) business operators. Producers, clients, and certification bodies jointly face a challenge to establish additional criteria to assess food safety, beyond the norms laid down in public regulation and thresholds for certification.

Given the limited experience with seaweed cultivation in the EU, two trajectories to identify criteria and thresholds beyond what is legally required are followed by the different companies in the seaweed sector. First, a reactive approach where food products are first brought to the market and criteria for food safety will be developed if incidents warrant such criteria. Secondly, a proactive approach where companies and certification bodies look toward adjacent sectors (in practice this refers to both fresh vegetables and shellfish) to identify food safety aspects that may become relevant for the seaweed sector.

\section{An Assessment From a Risk Governance Perspective}

The last question addressed in this section is to what extent do the current ways to govern the risks of seaweed production in a multi-use setting adhere to the principles of risk governance. The characterization of risks (Section "Which Risks Are of Concern to Respondents?") points to various systemic risks that are not suitable for traditional risk governance based on known causations. Of the five risks discussed, only pollution is a "simple risk," while the others are more "systemic risks" characterized by high levels of complexity, uncertainty, and/or ambiguity. The effect on biodiversity and pollution are two environmental risks that can influence food (and feed) safety concerns and could mean that seaweed produced may no longer be used for some food or feed purposes.

Evaluated from the perspective of three principles of risk governance: (1) communication and inclusion, (2) integration, and (3) reflection, the contemporary approach to deal with the risk of multi-use is considered disjointed. Current risk governance is based on a limited number of legal norms, on some legally prescribed procedures for assessing risks (EIA, HACCP) and a variety of private standards that are used by the sectors to secure safety. There are few legal norms, and private standards (often also based on legal norms) are often not specified for seaweed; hence, producers, processors, retailers and certification bodies find themselves on a joint journey to identify what comprises safe seaweed production. Some take this journey more serious than others and look for insights from adjacent markets and products.

\section{Communication and Inclusion}

Current risk governance is composed of a patchwork of norms, private standards, and certification schemes. The privatization of risk governance implies that information is not, by definition, openly shared. The associated costs for certification and required monitoring and control measures mean that some standards are not easily accessible for smaller companies, nor can they access the body of knowledge present with the companies that support and audit companies. Communication and inclusion of varying 
stakeholders is particularly pertinent to those risks that score high on complexity, uncertainty and/or ambiguity (i.e., ecosystem change due to sedimentation, decrease primary production, effect om biodiversity, impact on animals).

\section{Integration}

Mostly, current risk governance for environmental and associated food (and feed) safety risk of multi-use is the result of a fragmented set of actions by various stakeholders. Each of them gains expertise, e.g., in applying for standards or monitoring production, but hardly any efforts are made to integrate findings into a shared body of knowledge. Integration of knowledge is particularly urgent for effects on biodiversity (highly uncertain), as well as for the other, "medium uncertain" risks.

\section{Reflection}

When discussing the risks of seaweed production at an offshore wind farm, there is no long-standing history of real-life experiences. Also, the fragmented approach to risk governance suggests that it is too early for systematic reflection on the approach. Multiple stakeholders argue that at this stage of development, the seaweed sector should be given the room to experiment and develop further - without imposing strict (and costly) norms and standards. Still, if seaweed production at offshore wind farms is to grow into a significant industry, it does need regulation of safety aspects to minimize the chance of incidents as well as create trust among stakeholders along the chain and consumers. This process of reflecting is highly needed in cases of high uncertainty and/or ambiguity (i.e., effect on biodiversity, impact on animals).

\section{CONCLUSION}

This study set out to discuss strategies for governing safety aspects of interactions and cumulative effects of wind energy generation and seaweed production.

The question is what can be done to improve risk governance for the safety of seaweed production at a multi-use setting. Based on the analysis reported, the following recommendations for governing the risks of multi-use are formulated.

\section{Risk Governance Should Be Based on an Adaptive Framework for Risk Assessment to Deal With Complex, Systemic Risks}

The identified risks vary in nature, include systemic risks with high complexity, uncertainty, and ambiguity. Standard risk assessment methods - designed for simple risks - are therefore not usable in an offshore multi-use context; they would unjustly reduce risk to causes, effects, and probabilities omitting contextual factors of importance. For a proper understanding of (the complexity of) these risks, a participatory and interdisciplinary risk assessment is needed, including the systematic assessment of risks to human health, the environment, related concerns, and social and economic implications (cf. IRGC, 2005, 2007; Renn and Walker, 2008).

\section{Communication and Inclusion Must Be Supported}

The interdisciplinary assessment process should be informed by scientific analyses - but, in contrast to traditional/standard risk assessment models, the scientific process needs to include the natural, technical, and social sciences, as well as include stakeholder knowledge and experience. Current risk governance is characterized by the diversity of approaches using different standards and certificates. To some extent, this is a deliberate bottom-up choice of governments and businesses - giving room to the sector to develop on its own. The negative side effect of this is that many actors reinvent the wheel, not building upon experiences gained by others (e.g., when applying for a permit or certificate). Using these experiences in advancing risk governance is not only efficient, but it can also benefit inclusion of those companies for whom (multiple kinds of) certification is too expensive and thereby benefit the development of multi-use.

\section{Risk Governance Should Be a Joint Effort of Governments and Private Regulators}

In the current situation, a limited number of government norms is supplemented by private standards. Private standards, however, are generally procedural by nature; they prescribe procedures to follow, not norms to comply with. Governmental norms lie at the basis of these standards as they provide the legal framework to fall back on. For food safety, there is sufficient regulation, but there is a need to translate these to seaweed. For environmental issues, there are procedures for assessing the impact of individual sectors. Government regulation can raise the bar, whereas private standards can be instrumental in advertising or promoting a company that demands more than is formally required.

\section{Risk Governance Should Be Flexible and Adaptive to New Incoming Information}

Since the combination of seaweed production and offshore wind energy is as of now non-existent, discussions on the risks are hypothetical. The lack of practical experiences adds to the uncertainty around the related risks. Given the societal challenge to produce food for a growing world population and the spatial claims of offshore wind energy, the combined production of food and energy should be explored further. Risk governance that imposes strict standards beforehand - excluding everything that might possibly happen will render multi-use next to impossible. What is needed is an approach to risk governance that recognizes the systemic nature of risks without being overwhelmed by complexity, that is based on sharing of experiences, and that can be adapted to new incoming information.

\section{Integrated Assessments Should Be Used to Address Cumulative Effects and Scale-Effects}

Risk assessment tends to focus on individual activities (e.g., a wind farm) and individual risks. The ecosystem impact results 
from the totality of activities. Various approaches to EcosystemBased Management are developed (De Jonge et al., 2012; Piet et al., 2019). These integrated assessments can provide insight into scale-effects, cumulative effects, and the interactions between ecological, social, and economic risks.

\section{DATA AVAILABILITY STATEMENT}

The datasets generated for this study will not be made publicly available some of the datasets contain personal information.

\section{AUTHOR CONTRIBUTIONS}

All authors contributed to the research design and elaborated on the theoretical concepts. SV, CR, and JB have contributed to the data collection and analysis. All authors have contributed to drafting and finalizing the manuscript.

\section{REFERENCES}

Bak, U. G. (2018). Production method and cost of commercial-scale offshore cultivation of kelp in the faroe islands using multiple partial harvesting. Algal Res. 33, 36-47. doi: 10.1016/j.algal.2018.05.001

Beck, U. (1992). Risk Society: Towards a New Modernity. London: Sage Publications Ltd. doi: 10.1016/j.algal.2018.05.001

Beveridge, M. C. M., Phillips, M. J., and Macintosh, D. J. (1997). Aquaculture and the environment: the supply of and demand for environmental goods and services by asian aquaculture and the implications for sustainability. Aquacult. Res. 28, 797-807. doi: 10.1111/j.1365-2109.1997.tb01004.x

Bindu, M. S., and Levine, I. A. (2011). The commercial red seaweed kappaphycus alvarezii-an overview on farming and environment. J. Appl. Phycol. 23, 789-796. doi: 10.1007/s10811-010-9570-2

Bozzano, A. V. (2011). Design and Safety Assessment of Critical Systems. Boca Raton, FL: Taylor \& Francis Group.

Broström, G. (2008). On the influence of large wind farms on the upper ocean circulation. J. Mar. Syst. 74, 585-591. doi: 10.1016/j.jmarsys.2008.05.001

Buschmann, A. H., Camus, C., Infante, J., Neori, A., Israel, A., HernándezGonzález, M. C., et al. (2017). Seaweed production: overview of the global state of exploitation, farming and emerging research activity. Eur. J. Phycol. 52, 391-406. doi: 10.1080/09670262.2017.1365175

Buschmann, A. H., López, D. A., and Medina, A. (1996). A review of the environmental effects and alternative production strategies of marine aquaculture in chile. Aquacul. Eng. 15, 397-421. doi: 10.1016/S0144-8609(96) 01006- 1000

Cabral, P., Levrel, H., Viard, F., Frangoudes, K., Girard, S., and Scemama, P. (2016). Ecosystem services assessment and compensation costs for installing seaweed farms. Mar. Pol. 71, 157-165. doi: 10.1016/j.marpol.2016.05.031

De Jonge, V. N., Pinto, R., and Kerry Turner, R. (2012). Ocean \& coastal management integrating ecological, economic and social aspects to generate useful management information under the eu directives' 'ecosystem approach'. Ocean Coast. Manag. 68, 169-188. doi: 10.1016/j.ocecoaman.2012.05.017

Dreyer, M., and Renn, O. (2009). Food Safety Governance. Integrating Science, Precaution and Public Involvement. Heidelberg: Springer-Verlag.

Eklöf, J. S., De La Torre Castro, M., Adelsköld, L., Jiddawi, N. S., and Kautsky, N. (2005). Differences in macrofaunal and seagrass assemblages in seagrass beds with and without seaweed farms. Estuar. Coast. Shelf Sci. 63, 385-396. doi: 10.1016/j.ecss.2004.11.014

Eng, C. T. C., Paw, J. N., and Guarin, F. Y. (1989). The environmental impact of aquaculture and the effects of pollution on coastal aquaculture development

\section{FUNDING}

The work was co-funded by the Lloyd's Register Foundation under grant no. G\100123. The Foundation helps to protect life and property by supporting engineering-related education, public engagement, and the application of research. Results of the Knowledge Base Research program Marine Lower Trophic Food Systems (KB-34-007-004) are used.

\section{ACKNOWLEDGMENTS}

The researchers are thankful to all workshop participants and respondents for their input and feedback.

\section{SUPPLEMENTARY MATERIAL}

The Supplementary Material for this article can be found online at: https://www.frontiersin.org/articles/10.3389/fmars. 2020.00060/full\#supplementary-material

in Southeast Asia. Mar. Pollut. Bull. 20, 335-343. doi: 10.1016/0025-326X(89) 90157-90154

Furness, R. W., and Tasker, M. L. (2000). Seabird-fishery interactions: quantifying the sensitivity of seabirds to reductions in sandeel abundance, and identification of key areas for sensitive seabirds in the North Sea. Mar. Ecol. Prog. Ser. 202, 253-264. doi: 10.3354/meps202253

IRGC, (2005). White Paper on Risk Governance. Towards and Integrative Approach. Geneva: International Risk Governance Centre.

IRGC, (2007). Nanotechnology Risk Governance. Recommendations for a Global Coordinated Approach to the Governance of Potential Risks. Geneva: International Risk Governance Centre.

Jansen, H. M., Van Den Burg, S. W. K., Bolman, B., Jak, R. G., Kamermans, P., Poelman, M., et al. (2016). The feasibility of offshore aquaculture and its potential for multi-use in the North Sea. Aquacul. Intern. 24, 735-756. doi: 10.1007/s10499-016-9987-y

Kazir, M., Abuhassira, Y., Robin, A., Nahor, O., Luo, J., Israel, A., et al. (2018). Extraction of proteins from two marine Macroalgae, Ulva Sp. and Gracilaria Sp., for food application, and evaluating digestibility, amino acid composition and antioxidant properties of the protein concentrates. Food Hydrocoll. 87, 194-203. doi: 10.1016/J.FOODHYD.2018.07.047

Kim, J. G., Kraemer, G. P., and Yarish, C. (2014). Field scale evaluation of seaweed aquaculture as a nutrient boiextraction strategy in long island sound and the Bronx river estuary. Aquaculture 433, 148-156. doi: 10.1016/j.aquaculture. 2014.05.034

Klijnstra, J., Zhang, X., van der Putten, S., and Röckmann, C. (2017). “Technical risks of offshore structures," in Aquaculture Perspective of Multi-Use Sites in the Open Ocean: The Untapped Potential for Marine Resources in the Anthropocene, eds B. H. Buck, and R. Langan (Cham: Springer International Publishing), 115-127. doi: 10.1007/978-3-319-51159-7_5

Kontovas, C. A. (2008). Formal safety assessment: a critical review 1. Mar. Technol. $46,1-29$.

Lagerveld, S., Röckmann, C., and Scholl, M. (2014). A Study On the Combination of Offshore Wind Energy with Offshore Aquaculture. IMARES Report C056/14. Available at: http://edepot.wur.nl/318329 (accessed February 10, 2020).

Legorburu, I., Johnson, K. R., and Kerr, S. A. (2018). Multi-use maritime platforms - north sea oil and offshore wind: opportunity and risk. Ocean Coast. Manag. 160, 75-85. doi: 10.1016/j.ocecoaman.2018.03.044

Li, J. Y., Yang, F., Jin, L., Wang, Q., Yin, J., He, P., et al. (2018a). Safety and quality of the green tide algal species Ulva prolifera for option of human consumption: a nutrition and contamination study. Chemosphere 210, 1021-1028. doi: 10.1016/ j.chemosphere.2018.07.076 
Li, Q., Luo, J., Wang, C., Tai, W., Wang, H., Zhang, X., et al. (2018b). Ulvan extracted from green seaweeds as new natural additives in diets for laying hens. J. Appl. Phycol. 30, 2017-2027. doi: 10.1007/s10811-017-1365-2

Michler-Cieluch, T., Krause, G., and Buck, B. H. (2009). Reflections on integrating operation and maintenance activities of offshore wind farms and mariculture. Ocean Coast. Manag. 52, 57-68. doi: 10.1016/j.ocecoaman.2008.09.008

Netherlands Scientific Council for Government Policy [WRR], (2009). Uncertain Safety. Allocating. (Responsibilities) for Safety. Amsterdam: Amsterdam University Press.

OECD, (2003). Emerging Systemic Risks In the 21st Century: An Agenda for Action. Paris: OECD Publications service.

Offe, C. (2009). Governance: an 'Empty Signifier'? constellations. Claus Offe 16, 550-562. doi: 10.1111/j.1467-8675.2009.00570.x

Ólafsson, E., Johnstone, R. W., and Ndaro, S. G. M. (1995). Effects of intensive seaweed farming on the meiobenthos in a tropical lagoon. J. Exp. Mar. Biol. Ecol. 191, 101-117. doi: 10.1016/0022-0981(95)00055-V

Petersen, J. K., and Malm, T. (2006). Offshore windmill farms: threats to or possibilities for the marine environment. AMBIO 35, 75-80. doi: 10.1579/00447447200635

Piet, G., Culhane, F., Jongbloed, R., Robinson, L., Rumes, B., and Tamis, J. (2019). An integrated risk-based assessment of the north sea to guide ecosystem-based management. Sci. Total Environ. 654, 694-704. doi: 10.1016/j.scitotenv.2018.11. 001

Renn, O., and Klinke, A. (2004). Systemic risks: a new challenge for risk management. EMBO Rep. 5(Suppl. 1), S41-S46.

Renn, O., and Klinke, A. (2015). "Risk governance and resilience: new approaches to cope with uncertainty and ambiguity," in Risk Governance: The Articulation of Hazard, Politics and Ecology, ed. U. Fra.Paleo (Dordrecht: Springer), 19-41. doi: 10.1007/978-94-017-9328-5-2

Renn, O., Klinke, A., and Van Asselt, M. (2011). Coping with complexity, uncertainty and ambiguity in risk governance: a synthesis. Ambio 40, 231-246. doi: 10.1007/s13280-010-0134-0

Renn, O., and Walker, K. D. (2008). Global Risk Governance. Concept and Practice using the IRGC Framework. Dordrecht: Springer.

Roca, E., Gamboa, G., and Tàbara, J. D. (2008). Assessing the multidimensionality of coastal erosion risks: public participation and multicriteria analysis in a mediterranean coastal system. Risk Anal. 28, 399-412. doi: 10.1111/j.1539-6924. 2008.01026.x

Röckmann, C., Cado van der Lelij, A., Steenbergen, J., and van Duren, L. (2015). VisRisc - Estimating the Risks Of Introducing Fisheries Activities In Offshore Windparks. IMARES report C318/15 (in Dutch). Available at: http://library.wur. nl/WebQuery/wurpubs/fulltext/360260 (accessed February 10, 2020).

Roleda, M. Y., Marfaing, H., Desnica, N., Jónsdóttir, R., Skjermo, J., Rebours, C., et al. (2018). Variations in polyphenol and heavy metal contents of wildharvested and cultivated seaweed bulk biomass: health risk assessment and implication for food applications. Food Control 95, 121-134. doi: 10.1016/j. foodcont.2018.07.031

Stelzenmüller, V., Diekmann, R., Bastardie, F., Schulze, T., Berkenhagen, J., Kloppmann, M., et al. (2016). Co-location of passive gear fisheries in offshore wind farms in the german eez of the north sea: a first socio-economic scoping. J. Environ. Manage. 183, 794-805. doi: 10.1016/j.jenvman.2016.08.027

Stephens, D., Capuzzo, E., Aldridge, J., and Forster, R. M. (2014). Potential Interactions of Seaweed Farms With Natural Nutrient Sinks in Kelp Beds. London: The Crown Estate, 36.
Stuiver, M., Soma, K., Koundouri, P., van den Burg, S., Gerritsen, A., Harkamp, T., et al. (2016). The governance of multi-use platforms at sea for energy production and aquaculture: challenges for policy makers in european seas. Sustainability 8:333. doi: 10.3390/su8040333

van Asselt, M. B. A. (2007). Risk Governance: Over Omgaan Met Onzekerheid en Mogelijke Toekomsten. Maastricht: Universiteit Maastricht.

Van Asselt, M. B. A., and Renn, O. (2011). Risk Governance. J. Risk Res. 14, 431-449. doi: 10.1080/13669877.2011.553730

Van den Burg, S. W. K., and Röckmann, C. (2017). Overview of Safety Aspects of Interaction and Cumulative Effects. SOMOS Project Deliverable 3.1. IJmuiden: Wageningen Marine Research.

Van den Burg, S. W. K., van Duijn, A. P., Bartelings, H., van Krimpen, M. M., and Poelman, M. (2016). The economic feasibility of seaweed production in the North Sea. Aquacul. Econ. Manag 20, 235-252. doi: 10.1080/13657305.2016. 1177859

Vanhellemont, Q., and Ruddick, K. (2014). Remote sensing of environment turbid wakes associated with offshore wind turbines observed with landsat 8. Remote Sens. Environ. 145, 105-115. doi: 10.1016/j.rse.2014.01.009

Vredeveldt, A. W., Lassing, B. L., and Nelisse, R. M. L. (2017). Marine Exploration Hazards Factsheet. SOMOS Project Deliverable 2.2. Available at: https://www.wur.nl/upload_mm/0/7/a/870db7df-1027-456f-bf3b82a5012ca181_D2.2\%20Marine\%20exploration\%20hazards\%20factsheet.pdf (accessed February 10, 2020).

Wan, A. H. L., Davies, S. J., Soler-Vila, A., Fitzgerald, R., and Johnson, M. P. (2018). Macroalgae as a sustainable aquafeed ingredient. Rev. Aquacul. 11, 458-492. doi: $10.1111 /$ raq. 12241

Wells, M. L., Potin, P., Craigie, J. S., Raven, J. A., Merchant, S. S., Helliwell, K. E., et al. (2017). Algae as nutritional and functional food sources: revisiting our understanding. J. Appl. Phycol. 29, 949-982. doi: 10.1007/s10811-016-0 974-5

Wever, L., Krause, G., and Buck, B. H. (2015). Lessons from stakeholder dialogues on marine aquaculture in offshore wind farms: perceived potentials, constraints and research gaps. Mar. Policy 51, 251-259. doi: 10.1016/j.marpol.2014.0 8.015

Wood, D., Capuzzo, E., Kirby, D., Mooney-McAuley, K., and Kerrison, P. (2017). UK macroalgae aquaculture: what are the key environmental and licensing considerations? Mar. Policy 83, 29-39. doi: 10.1016/j.marpol.2017. 05.021

Zhang, J., Hansen, P. K., Fang, J., Wang, W., and Jiang, Z. (2009). Assessment of the local environmental impact of intensive marine shellfish and seaweed farming-application of the MOM system in the sungo Bay, China. Aquaculture 287, 304-310. doi: 10.1016/j.aquaculture.2008.10.008

Conflict of Interest: The authors declare that the research was conducted in the absence of any commercial or financial relationships that could be construed as a potential conflict of interest.

Copyright (C) 2020 van den Burg, Röckmann, Banach and van Hoof. This is an open-access article distributed under the terms of the Creative Commons Attribution License (CC BY). The use, distribution or reproduction in other forums is permitted, provided the original author(s) and the copyright owner(s) are credited and that the original publication in this journal is cited, in accordance with accepted academic practice. No use, distribution or reproduction is permitted which does not comply with these terms. 